\title{
EXPLORING NEW MARKETS: DIRECT \\ INVESTMENT, CONTRACTUAL RELATIONS AND THE MULTINATIONAL ENTERPRISE
}

\author{
Ignatius J. Horstmann \\ James R. Markusen
}

Working Paper No. 5029

\section{NATIONAL BUREAU OF ECONOMIC RESEARCH 1050 Massachusetts Avenue \\ Cambridge, MA 02138 \\ February 1995}

The first draft of this paper was written when Markusen was a visitor at the Institute for International Economic Studies, Stockholm and thanks the Institute members for their generous hospitality and comments. The research was financed by Markusen's NSF grant SES-9022898. This paper is part of NBER's research programs in International Finance and Macroeconomics and Public Economics. Any opinions expressed are those of the authors and not those of the National Bureau of Economic Research.

(C) 1995 by Ignatius J. Horstmann and James R. Markusen. All rights reserved. Short sections of text, not to exceed two paragraphs, may be quoted without explicit permission provided that full credit, including (C) notice, is given to the source. 


\title{
EXPLORING NEW MARKETS: DIRECT \\ INVESTMENT, CONTRACTUAL RELATIONS \\ AND THE MULTINATIONAL ENTERPRISE
}

\begin{abstract}
We consider the multinational firm's decision on whether to enter a new market immediately via direct investment or to contract initially with a local agent and (possibly) invest later. Use of a local agent allows the multinational to avoid costly mistakes by finding out if the market is large enough to support direct investment. However, the agent is able to extract information rents from the multinational due to being better informed about market characteristics. We find that direct investment is the desirable mode of entry when the market is on average large and there is little down-side risk in expected profits.
\end{abstract}

Ignatius J. Horstmann

Department of Economics University of Western Ontario

London, Ontario N6A 5C2

CANADA
James R. Markusen Department of Economics University of Colorado Boulder, CO 80309-0256 and NBER 
Exploring New Markets: Direct Investment, Contractual Relations and the Multinational Enterprise

\section{Introduction}

A fundamental problem in the theory of the multinational corporation is why these firms exist at all. If there are inherent costs of doing business abroad, then foreign markets should be served either by exports or by local producers in these markets. The traditional explanation for multinational firms rests on the existence of firm-specific, intangible assets that give these firms off-setting cost advantages over foreign-country producers (see Caves (1982)). These assets often take the form of knowledge capital within the firm, this capital being either production based and arising from $\mathrm{R} \& \mathrm{D}$ activity and managerial/engineering experience or consumer based and the result of product differentiation, brand reputation and so forth. The existence of these capital assets gives the firm multi-plant economies of scale (the cost advantage) in that the services of this knowledge-based capital can be cheaply transferred to foreign locations.

While the existence of knowledge-based capital may explain multinational firms, it does not, by itself, explain why a firm would wish to make a large investment in a foreign branch plant (or even a direct sales branch) versus simply contracting for production and sales with a host-country entrepreneur. One reason the firm may choose direct investment over some arm's-length arrangement is that the latter is subject to agency costs that the former avoids. For instance, the public-goods nature of knowledge capital may produce agency problems involving dissipation of that capital by licensees. Horstmann and Markusen (1987) argue 


\section{Exploring New Markets: Direct Investment, Contract ual Relations and the Multinational Enterprise}

that, because a licensee will not fully appropriate the returns from maintaining the firm's brand reputation, it will dissipate that reputation in circumstances in which it is in the firm's interest to maintain it. Ethier and Markusen (1992) support direct investment based on the inability of the multinational to prevent a foreign licensee from "learning-by-doing" and so defecting to become a local competitor for the firm. ${ }^{1}$

In this paper, we provide an alternative agency explanation for the multinational firm's choice between direct investment and an arm's-length agreement. Here, the multinational firm may adopt some contractual arrangement with a local agent as a means of exploiting any superior information the agent may possess regarding market characteristics. The cost of such an arrangement to the firm is that the local agent can use this superior information to extract some of the multinational rents The choice for the multinational then turns on whether the savings that result from learning about the market through the agency arrangement are more than dissipated by the agency costs that the contract produces.

The setting is one in which a firm is seeking to sell its product in a new (foreign) market. Because it is entering a new market, the firm is uncertain about the revenues it can expect to generate. In entering the market, it can either choose to invest immediately in its own sales operation or it can contract for sales via a local agent. The local agent, having experience in the market, has information on market characteristics not available to the multinational.

1 Good collections of articles that examine investment and internalization are found in Casson (1990) and Buckley (1990). Casson (1987) presents a comprehensive study of FDI. An interesting survey on multinationals is presented in The Economist, March 27-April 2, 1993. In a section of this survey article entitled "Creatures of Imperfection", the authors note that the principal paradox is why we have seen such a tremendous expansion of direct investment in a world where trade barriers have fallen dramatically. "The solution to this puzzle is that multinationals are not exploiters of purity but rather creatures of market imperfections, or failures". (p. 9 of the Survey). 


\section{Exploring New Markets: Direct Investment, Contractual Relations and the Multinational Enterprise}

Within this setting, we derive both the optimal multi-period agency contract and the optimal mode of entry for the multinational. Because one often observes in the data that agency contracts are of limited duration, the contract allows for the possibility of non-renewal at some future date. The analysis includes a consideration of the determinants of any nonrenewal decision as well as the multinationals choice between the contract and immediate direct investment.

As previous discussion would suggest, the multinational's decision regarding initial entry mode depends on the size of the returns to information gathering relative to the rents that the agent can be expected to extract. Things that make investment mistakes more costly, like large set-up costs relative to market size/revenues or easy escape from any contractual obligations, make a contract a more attractive. Things that increase the returns to having superior information, like large up-side risk in sales revenue, increase agency costs and so make immediate investment attractive. Thus, the model predicts that a contractual arrangement is more likely when markets are on average small, there is large down-side risk in sales revenue and conversion from a contractual arrangement to owned sales operations can be achieved quickly. Further, if non-renewal of the contract occurs, it occurs when past sales are relatively large.

Although there have been no empirical studies (to the best of our knowledge) that explicitly focus on the ideas developed here, there is considerable evidence pointing to the empirical relevance of the model. Nicholas $(1982,1983)$ notes that, among his sample of British multinational firms operating during the pre- 1939 period, $88 \%$ sold their products 


\section{Exploring New Markets: Direct Investment, Contractual Relations and the Multinational Enterprise}

initially under a contract with a local agent in the foreign country before converting to direct sales or production branches. Initial agency contracts were renewed in a high percentage of cases (70-80\%) and in instances where conversion to direct investment did occur, the period of agency varied from 4 to 25 years. According to Nicholas, the historical record indicates that the decision not to renew was a conscious one on the multinational's part (as opposed to being the result of business failure by the agent) based both on a desire by the firm to avoid agency costs and on its having learned, through the agency arrangement, that information on local market characteristics that made the agency contract valuable in the first place.

Zeile (1993) documents a modern tendency for many foreign firms exporting to the United States to use direct sales branches to control the wholesaling and distribution of their products. While he provides no comparable data on the use of agents or licensees, this study at least points to the quantitative importance of the direct sales branch mode of foreign operations. At the same time, survey data on Australian firms' business experiences in East Asia by Thompson (1994) and McIntosh/Baring (1993) provide evidence of the potential problems arising from various contractual arrangements with foreign partners. These problems include the reliability of information, distribution, promotion, and servicing issues. In general, the Australian firms felt disadvantaged by their own ignorance of the Asian markets. The studies recommend the use of local agents only for relatively short-term projects and/or ventures involving commodity products. Direct investment with majority control is found to be important for long-term projects and/or those involving more complex production and servicing. 
Finally, Nicholas et al. (1994) provide survey data on direct investment by Japanese multinationals in Australia (a small but high-income market). Of those firms responding, $60 \%$ indicated that they used an Australian agent for some period of time before making any direct investment and $69 \%$ indicated that they exported to Australia using a trading company before making their investment.

We should also note a related theoretical literature regarding information gathering in new product markets and the firm's investment decision. McGahan (1993) considers whether a new product monopolist should engage in immediate, large-scale investment that would deter entry by future competitors or explore the market initially with prototypes requiring smaller capacity investments and only invest further if the market proves large. While entry deterrence is not an issue in our model, it has the same information gathering features as McGahan's model.

The specifics of our model are detailed in the next section. Section 3 provides the optimal agency contract when non-renewal is not possible while the optimal contract given the possibility of non-renewal is derived in section 4 . The determinants of the multinational's decision regarding direct investment versus contracting is also analyzed in section 4 . Section 5 provides some concluding remarks.

\section{The Foreign Sales Model}

We consider a situation in which a producer (the MNE) of an established product, $X$, located in Country 1 (the home country) has decided to sell this product in Country 2 (the 


\section{Exploring New Markets: Direct Investment, Contractual Relations and the Multinational Enterprise}

foreign country), a market in which the MNE has no previous sales experience. Among the options for selling in the foreign country, two are potentially most profitable: contracting with a local sales agent or establishing an owned local sales operation. The foreign market is characterized by a potential pool, $N_{i}$, of identical customers with individual demand functions given by the expression $x=f(p)$, where $x$ is the quantity demanded of $X$ by any individual customer if the price of $X$ is $p$. Because the product is an established one, the characteristics of the demand function are known to both the MNE and any potential local sales agent. Such is not the case for the size of the potential customer pool, $N_{i}$. The sales agent is assumed to know the value of $N_{i}$, due perhaps to past experience in the local market; the MNE, on the other hand, is initially uninformed as to its actual value. The MNE does know the distribution of values for $N_{i}$, however. For simplicity, this distribution is assumed such that $N_{i}$ may take on one of two possible values: $N_{1}$ and $N_{2}>N_{1}$. The probability that $N_{i}=N_{1}$ is given by $\rho$ with $0<\rho<1 .^{2}$

While the potential customer pool is of a fixed size (either $N_{1}$ or $N_{2}$ ), the number of customers to actually purchase the MNE's product is a variable that depends on sales effort. In particular, it is assumed that the number of actual customers is proportional to the size of the potential customer pool, with the variable of proportionality depending on sales effort. Because it is possible that the local sales agent and the MNE's own sales force have differential abilities at generating customers, the variable of proportionality is allowed to depend on whether the product is sold by the local sales agent or via the MNE's owned

2 The assumption that the asymmetric information involves the size of the potential customer pool is not crucial to what follows. The analysis would equally well apply to a situation in which the potential customer pool is of a known size but some parameter of the demand function is known only to the agent. 


\section{Exploring New Markets: Direct Investment, Contract ual Relations and the Multinational Enterprise}

sales operation. If a local agent is employed and the potential customer pool is $N_{i}$, then the number of actual customers, $n_{i}$, is given by the expression $n_{i}=e_{a} N_{i}$, where $e_{a}$ is the local agent's sales effort and is normalized such that $0 \leq e_{a} \leq 1$. If the MNE uses its own sales force, then the number of actual customers is given by $n_{i}=\alpha e_{m} N_{i}$, where $e_{m}$ is measured in the same units as $e_{a}$ and $\alpha e_{m}$ gives efficiency units of sales effort by the MNE's sales force. A value of $\alpha>1$ would indicate that the MNE's sales force is more efficient at producing customers than the local agent, due perhaps to greater experience or familiarity with the product. Alternatively, a value of $\alpha<1$ would indicate that the MNE's sales force is less efficient, perhaps as a result of less familiarity with local conditions. Sales effort is costly for both the local agent and the MNE's own sales force, with the cost of effort given by the function $C=c\left(e_{j}\right), \quad j=a, m$. The effort cost function is assumed to be increasing and strictly convex with $c^{\prime}(0)=0$.

Finally, it is assumed that the cost of establishing a sales operation in the foreign country depends on the choice of sales mode. Should the MNE establish its own sales operation, then it incurs a one-time set-up cost of $G \geq 0$. This cost represents a sunk cost and captures such things as legal costs, cost of dealing with bureaucratic red-tape, any specific investment costs and the like. In addition, it incurs a per-period fixed cost of $F \geq 0$, representing various administrative and overhead costs and any costs of compensating its own sales force for foregone alternative opportunities. In contrast, the local sales agent, having already established its operation and already incurring various costs due to other contracts, is assumed able to add the MNE's contract with no additional set-up costs ( $G=0$ for the 


\section{Exploring New Markets: Direct Investment, Contractual Relations and the Multinational Enterprise}

local agent). In essence, set-up costs are assumed to result from establishing and operating a sales agency and not from adding an additional product to the sales line. The local agent does incur a fixed cost of $R \geq 0$ from adding the MNE's product that represents any added administrative costs for the agent as well as costs of the agent's foregone alternatives (perhaps not entering into an alternative contractual arrangement). Beyond these costs (and the sales effort costs), it is assumed that neither the MNE nor the local agent incur any other direct costs in producing or marketing the product. It is also assumed that the MNE (or its agent) faces no competition (either actual or potential) for its product in the foreign country. ${ }^{3}$

The model implies that, in making a decision on the form of foreign sales operations, the MNE is confronted with a trade-off. The sales agent has the advantage of having better information regarding market size as well as having lower set-up costs. These features favor the agency contract. On the other hand, the use of a sales agent must inevitably result in agency costs for the MNE arising from the agent's ability to exploit this better information. In addition, the agent may be less efficient at producing customers than the MNE. These features favor an ownership arrangement. In what follows, we explore the nature of this trade-off, considering it first in a situation in which the MNE can only choose between a once-for-all contract with the agent or the permanent establishment of an owned sales operation. We then ask whether (and under what circumstances) the MNE can do better by using a non-renewable, short-term contract.

3 This assumption means that the MNE's decision regarding sales mode turns purely on the magnitude of the agency costs implied by different contract forms relative to the costs of establishing an owned sales operation. The use of particular agency contracts by the MNE as a means of deterring entry (a la Aghion and Bolton (1987)) is not an issue here. 


\section{Exploring New Markets: Direct Investment, Contractual Relations and the Multinational Enterprise}

\section{A One-Period Choice Problem}

To help define some of the issues involved in the MNE's choice of sales mode, it is useful to consider first a simple one-period problem. One can think of this problem as providing the solution to the optimal multi-period contracting problem when the MNE is restricted either to contracting once-for-all with a local sales agent or permanently establishing an owned foreign sales operation.

To begin, we consider the optimal contract should the MNE choose to employ a local sales agent in the foreign country. A contract, in this case, is assumed to specify a price, $p$, at which $X$ will be sold, a quantity, $q$, of $X$ that will be sold and a transfer, $w$, from the MNE to the local sales agent (the sales agent is assumed to remit all sales revenues to the MNE). By the revelation principle, ${ }^{4}$ the optimal contract can be found by a consideration of those contracts in which the values of $p, q$ and $w$ are conditioned only on the agent's report of market size, $N_{i}$. Because the individual demand function is known by both parties and the profit-maximizing price is independent of $N_{i}$, the value of $p$ specified in the optimal contract will be independent of $N_{i}$. To save on notation, $p$ will, therefore, be suppressed in the description of the optimal contract that follows. The optimal contract, then, is described by a menu $\left\langle q\left(N_{i}\right), w\left(N_{i}\right)\right\rangle$ that satisfies both incentive compatibility (IC) and individual rationality (IR). ${ }^{5}$ The agent is assumed to choose one $(q, w)$ pair from this menu, choosing

4 The revelation principle states that any allocation that would arise as a Nash equilibrium outcome of a game with communication can be recovered via a game in which i) allocations depend only on agents' reports of type (their private information) and ii) the allocation rule satisfies incentive compatibility (agents report types truthfully) and individual rationality (agents are willing to participate). For more details, see Myerson (1991) p. $255 \mathrm{ff}$..

5 The assumption that the parties are able to contract on the actual quantity sold may seem somewhat unrealistic. However, a contract specifying an initial payment by the MNE to the sales agent when the 


\section{Exploring New Markets: Direct Investment, Contract ual Relations and the Multinational Enterprise}

the one that maximizes utility. Both the MNE and the local agent are assumed risk neutral and the menu chosen by the MNE is the one that maximizes its expected profits. It is assumed that the value of $R$ is not so large as to make contracting with the agent always unprofitable for the MNE.

To solve for the optimal contract, note that an agent facing a potential customer pool of size $N_{i}$, having contracted to sell a quantity $q_{i}$, must engage in sales effort given by the expression $e_{a}=q_{i} / f(p) N_{i}{ }^{6}$ If units of $X$ are normalized such that, at the profit-maximizing $p, f(p)=1$, sales effort simplifies to $e_{a}=q_{i} / N_{i}$. Then, the optimal contract is defined as the solution to the following maximization problem:

$$
\max _{q_{1}, q_{2}, w_{1}, w_{2}} E \pi=\rho\left(p q_{1}-w_{1}\right)+(1-\rho)\left(p q_{2}-w_{2}\right)
$$

subject to

$$
\begin{gathered}
w_{1}-c\left(q_{1} / N_{1}\right) \geq w_{2}-c\left(q_{2} / N_{1}\right) \\
w_{2}-c\left(q_{2} / N_{2}\right) \geq w_{1}-c\left(q_{1} / N_{2}\right) \\
w_{1}-c\left(q_{1} / N_{1}\right) \geq R \\
w_{2}-c\left(q_{2} / N_{2}\right) \geq R
\end{gathered}
$$

where the first two constraints are the two incentive compatibility conditions and the last two the individual rationality constraints.

contract is signed as well as a quantity of the good that the agent must purchase from the MNE each period and a purchase price would exactly mimic the contract defined below.

6 In what follows, we will use the notation $\left(q_{i}, w_{i}\right)$ as a shorthand to describe the contract $\left\langle q\left(N_{i}\right), w\left(N_{i}\right)\right\rangle$, the pair offered should the agent report a customer pool of size $N_{i}$. 


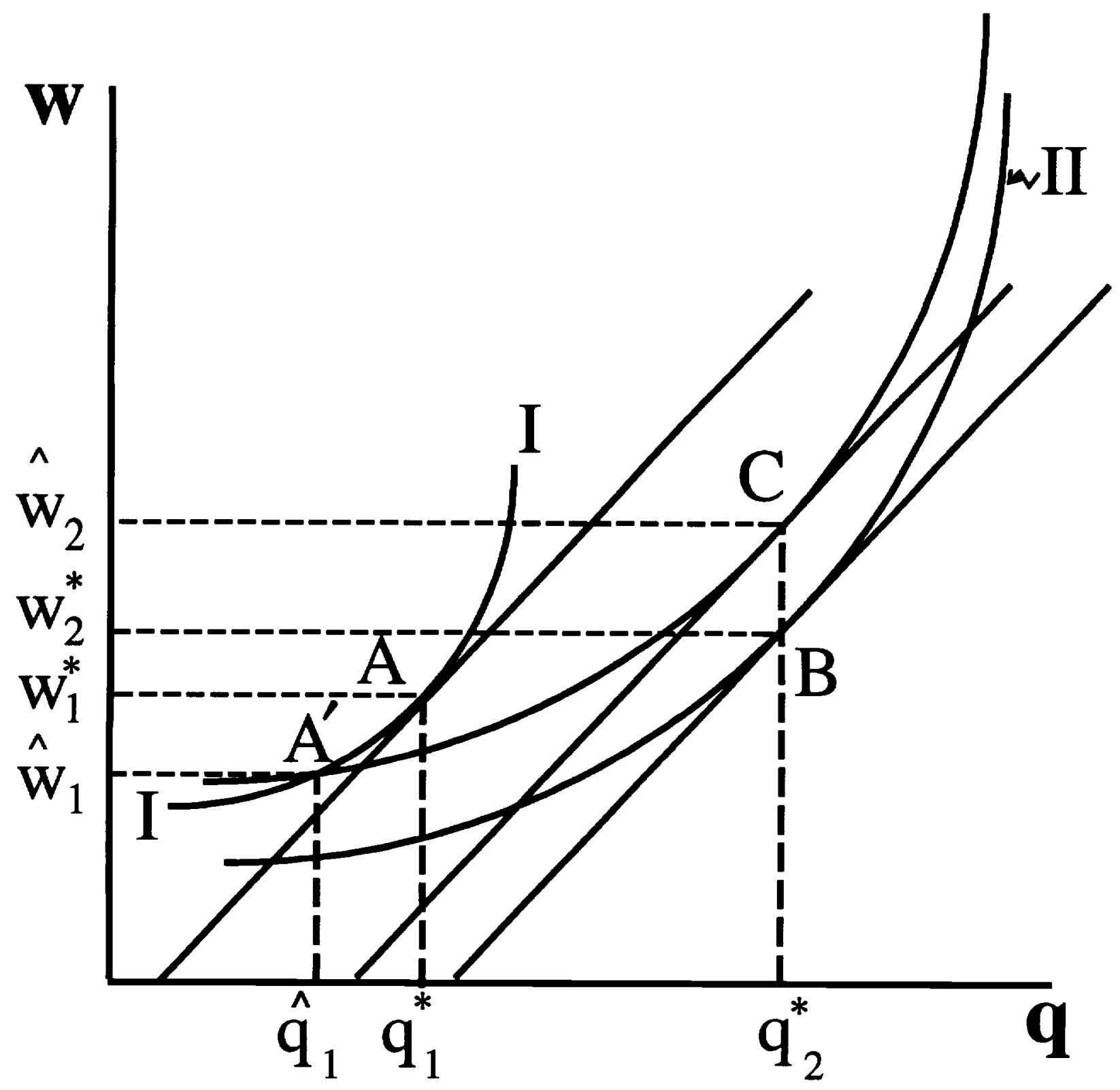

Curve I such that $w-c\left(q / N_{1}\right)=R$; curve II such that $\mathrm{w}-\mathrm{c}\left(\mathrm{q} / \mathrm{N}_{2}\right)=\mathrm{R}$.

Figure 1 


\section{Exploring New Markets: Direct Investment, Contract ual Relations and the Multinational Enterprise}

The solution to this problem can be illustrated diagrammatically. ${ }^{7}$ Consider Figure 1. The straight lines in the figure represent the MNE's iso-profit curves in $(w, q)$ space while the curves give the indifference curves for an agent. There are two sets of indifference curves, one when the value of $N_{i}$ is $N_{1}$ and one when $N_{i}=N_{2}$. The slope of an indifference curve is given by the expression $\frac{1}{N_{i}} C^{\prime}\left(q / N_{i}\right)$, so that the indifference curves for $N_{i}=N_{2}$ are flatter than those for $N_{i}=N_{1}$. Point A gives the MNE's profit maximizing contract when the customer pool is known to be of size $N_{1}$; point B gives the profit maximizing contract when the pool is known to be $\mathrm{N}_{2}{ }^{8}$ Since a given increase in effort generates a larger increase in sales the larger is $N_{i}$, it is profitable for the MNE to have the agent expend more sales effort in the market with the larger customer pool. As a result, $q_{2}^{*}>q_{1}^{*}$ and $w_{2}^{*}>w_{1}^{*}$. This same fact regarding the technology of sales production means that, should the agent facing a customer pool of $N_{2}$ obtain the contract $\left(q_{1}^{*}, w_{1}^{*}\right)$, utility is larger than $R$ (less sales effort is required to produce $q_{1}^{*}$ ). Thus, the indifference curve through point B (curve II) passes below point $\mathrm{A}$.

This last feature of the full-information contracts means that the MNE can never implement it if the value of $N_{i}$ is unknown. If faced with the prospect of $\left(q_{2}^{*}, w_{2}^{*}\right)$, the agent will always select the contract $\left(q_{1}^{*}, w_{1}^{*}\right)$ instead. In general, because the existence of private information means that the contract offer must induce agents to self-select, the MNE will be able to extract all of the surplus from the agent when $N_{i}=N_{1}$, but only enough surplus

7 For a formal treatment of this problem, see Horstmann and Markusen (1992).

8 It is assumed that the effort cost function is sufficiently convex that the profit-maximizing contract is an interior point. In this case, the contract occurs where the MNE's iso-profit line is tangent to the indifference curve giving $R$ units of utility. 


\section{Exploring New Markets: Direct Investment, Contractual Relations and the}

Multinational Enterprise

when $N_{i}=N_{2}$ to make the agent indifferent between accepting $\left(q_{2}, w_{2}\right)$ and claiming that the potential customer pool is $N_{1}$ (in particular, the surplus must be greater than $R$ ). In terms of the problem (C1) above, the profit-maximizing set of contracts will be such that only the first individual rationality constraint $\left(\mathrm{IR}_{1}\right)$ and the second incentive compatibility constraint $\left(\mathrm{IC}_{2}\right)$ are binding. In terms of the diagram, the set of contracts will be such that $\left(q_{1}, w_{1}\right)$ lies on indifference curve I (IR $\mathrm{IR}_{1}$ binds) and both of $\left(q_{1}, w_{1}\right),\left(q_{2}, w_{2}\right)$ lie on a single indifference curve for $N_{i}=N_{2}$ ( $\mathrm{IC}_{2}$ binds).

The actual profit-maximizing contracts are given by the points $\mathrm{C}$ and $\mathrm{A}^{\prime}$. Note that $q_{1}<q_{1}^{*}$ while $q_{2}=q_{2}^{*}$. This outcome results from the fact that, at point A, a decrease in $q$ and $w$ along indifference curve I has no impact on the MNE's expected profits at the margin when $N_{i}=N_{1}$ (this is just an envelope argument). However, because the agent's indifference curves are flatter when $N_{i}=N_{2}$, the reduction makes the contract $\left(q_{1}, w_{1}\right)$ less attractive to the agent facing a customer pool of $N_{2}\left(\mathrm{IC}_{2}\right.$ is relaxed). As a result, the MNE can offer a contract $\left(q_{2}, w_{2}\right)$ with $q_{2}=q_{2}^{*}$ but $w$ lower than would be needed if $q_{1}=q_{1}^{*}$ and still have it accepted when $N_{i}=N_{2}$. The lower $w$ means that, on net, expected profits rise from the reduction in $q_{1}$. Because changes in $q_{2}$ relax no constraints, its value remains at $q_{2}^{*}$. For the same reasons as in the full-information contract, $w_{2}>w_{1}$.

How does the MNE rank this contract relative to direct investment via the establishment of an owned sales operation? Suppose that part of the cost of setting-up operations for the MNE (i.e., part of the sunk cost, $G$ ) is determining the size of the potential customer pool. ${ }^{9}$ Suppose, also, that $F$ is not so large as to make selling in the foreign country unprofitable $\overline{9}$ 


\section{Exploring New Markets: Direct Investment, Contractual Relations and the Multinational Enterprise}

if $N_{i}=N_{1}$ (although $F+G$ may well be so) and that $\alpha=1$. Then, under the equilibrium contract, the quantity sold should $N_{i}=N_{2}$ is the same as if the MNE establishes its own sales operation. However, the MNE must compensate the sales agent not only an amount $R$ but some additional amount that is an information rent earned by the local agent. If $N_{i}=N_{1}$, while the agent earns no information rent $\left(w_{1}=R\right)$, the quantity sold under the contract is smaller than the amount the MNE would sell with its own sales force $\left(q_{1}<q_{1}^{*}\right)$. Thus, even were $R=0$, the MNE can expect one of two possible types of agency costs under the equilibrium contract: the information rents earned by the agent should $N_{i}=N_{2}$ and the inefficiently low level of sales if $N_{i}=N_{1}$. These costs must be traded-off against the extra costs of establishing an owned sales operation, $F+G$.

If $\alpha>1$, so that the MNE's own sales force is more efficient than the local agent, direct investment is additionally desirable relative to the above situation. Conversely, if $\alpha<1$ the MNE's own sales force is less efficient than the local agent - direct investment is less desirable. Rather than considering here the circumstances under which the MNE prefers a contract to direct investment, we will delay this issue until the next section when the MNE has the option of using short-term contracts.

This assumption simply makes comparisons easier in that it implies that the MNE's sales force is making effort choices with the same information as the local agent. 


\section{Exploring New Markets: Direct Investment, Contractual Relations and the}

Multinational Enterprise

\section{The Multi-Period Choice Problem}

\subsection{The contracting problem}

In the contract setting above, should the MNE learn through the agency arrangement that the market is large enough to make an owned sales operation profitable, it is unable to take advantage of this information - the contract is a once-for-all contract. This fact makes the contract more costly and makes immediate FDI an attractive alternative. A contract that is of limited duration, on the other hand, allows the MNE to utilize information acquired through the agency relationship by switching to an owned sales operation if this option is found to be more profitable. This feature of a short-term contract makes its initial use an attractive option for the MNE. In what follows, we explore whether and under what circumstances the MNE will choose this short-term contracting option as a means of entering a foreign market.

To proceed, we assume that MNE is now to be able to offer the agent a non-renewable contract of finite length in addition to the infinite length contracts available previously. Because of this additional option, a contract is now a triple $\left\langle q\left(N_{i}\right), w\left(N_{i}\right), T\left(N_{i}\right)\right\rangle$ where, as before, $q(\cdot)$ gives per-period sales and $w(\cdot)$ the per-period transfer from the MNE to the local agent. The variable $T(\cdot)$ gives the last period for which the contract is in force. In what follows, we will use the abbreviated form $\left(q_{i}, w_{i}, T_{i}\right)$ to represent this contract.

As in the previous section, the MNE's equilibrium contract offer is defined as the one that maximizes its expected profits subject to the appropriate individual rationality and incentive compatibility constraints. This contract is given by the solution to the following 


\section{Exploring New Markets: Direct Investment, Contract ual Relations and the Multinational Enterprise}

maximization problem:

$\max \rho\left[\sum_{t=0}^{T_{1}}\left(p q_{1}-w_{1}\right) \delta^{t}+\delta^{T_{1}+1}\left(\frac{\pi_{1}}{1-\delta}-G\right)\right]+(1-\rho)\left[\sum_{t=0}^{T_{2}}\left(p q_{2}-w_{2}\right) \delta^{t}+\delta^{T_{2}+1}\left(\frac{\pi_{2}}{1-\delta}-G\right)\right]$ subject to

$$
\begin{gathered}
\sum_{t=0}^{T_{1}}\left[w_{1}-c\left(q_{1} / N_{1}\right)\right] \delta^{t}+\sum_{t=T_{1}+1}^{\infty} R \delta^{t} \geq \sum_{t=0}^{T_{2}}\left[w_{2}-c\left(q_{2} / N_{1}\right] \delta^{t}+\sum_{t=T_{2}+1}^{\infty} R \delta^{t}\right. \\
\sum_{t=0}^{T_{2}}\left[w_{2}-c\left(q_{2} / N_{2}\right)\right] \delta^{t}+\sum_{t=T_{2}+1}^{\infty} R \delta^{t} \geq \sum_{t=0}^{T_{1}}\left[w_{1}-c\left(q_{1} / N_{2}\right)\right] \delta^{t}+\sum_{t=T_{1}+1}^{\infty} R \delta^{t} \\
\sum_{t=0}^{T_{1}}\left[w_{1}-c\left(q_{1} / N_{1}\right)\right] \delta^{t}+\sum_{t=T_{1}+1}^{\infty} R \delta^{t} \geq \frac{R}{1-\delta} \\
\sum_{t=0}^{T_{2}}\left[w_{2}-c\left(q_{2} / N_{2}\right)\right] \delta^{t}+\sum_{t=T_{2}+1}^{\infty} R \delta^{t} \geq \frac{R}{1-\delta}
\end{gathered}
$$

In the above formulation, $\pi_{1}$ represents the MNE's per-period profit from its owned sales operation should $N_{i}=N_{1}$. It is defined by $\pi_{1}=\max _{q} p q-C\left(q / \alpha N_{1}\right)-F$; the variable $\pi_{2}$ is defined analogously. The variable $\delta \in(0,1)$ is a common discount factor. Also built in to the above problem is the assumption that the local sales agent can take advantage of the best alternative opportunity once the MNE terminates the sales contract. The alternative assumption that the local sales agent loses this opportunity upon contracting with the MNE could easily be incorporated into the above problem.

By arguments identical to those employed in the preceding section, one can show that $I R_{1}$ and $I_{2}$ bind (the second and third constraints above) and that $I_{2}$ (the last constraint) does not bind. In contrast to the previous problem, $\mathrm{IC}_{1}$ (the first constraint) may or may not bind; however, a necessary condition for $\mathrm{IC}_{1}$ to bind is that $T_{1}>T_{2}{ }^{10}$ In what follows, we 10 


\section{Exploring New Markets: Direct Investment, Contractual Relations and the Multinational Enterprise}

assume that $\mathrm{IC}_{1}$ does not bind. However, we note at various points in the discussion to follow how our results would be affected were $\mathrm{IC}_{1}$ binding. Given these observations and, again, letting $\lambda_{1}$ be the Lagrange multiplier for $\mathrm{IR}_{1}$ and $\lambda_{2}$ the multiplier for $\mathrm{IC}_{2}$, the conditions defining the pairs $\left(q_{1}, w_{1}\right),\left(q_{2}, w_{2}\right)$ for the equilibrium multi-period contract are:

$$
\begin{gathered}
\frac{\partial L}{\partial q_{1}}=\left[\rho p+\lambda_{2} c^{\prime}\left(q_{1} / N_{2}\right) \frac{1}{N_{2}}-\lambda_{1} c^{\prime}\left(q_{1} / N_{1}\right) \frac{1}{N_{1}}\right] \frac{1-\delta^{T_{1}+1}}{1-\delta}=0 \\
\frac{\partial L}{\partial w_{1}}=\left[-\rho-\lambda_{2}+\lambda_{1}\right] \frac{1-\delta^{T_{1}+1}}{1-\delta}=0 \\
\frac{\partial L}{\partial q_{2}}=\left[(1-\rho) p-\lambda_{2} c^{\prime}\left(q_{2} / N_{2}\right) \frac{1}{N_{2}}\right] \frac{1-\delta^{T_{2}+1}}{1-\delta}=0 \\
\frac{\partial L}{\partial w_{2}}=\left[-(1-\rho)+\lambda_{2}\right] \frac{1-\delta^{T_{2}+1}}{1-\delta}=0
\end{gathered}
$$

These conditions are identical to those defining the optimal values of $q_{1}$ and $q_{2}$ in the once-forall contracting problem of the previous section. Thus, as before, $q_{2}=q_{2}^{*}$ while $q_{1}=\widehat{q}_{1}<q_{1}^{*}$. The values of $w_{1}$ and $w_{2}$ are those that make $\mathrm{IR}_{1}$ and $\mathrm{IC}_{2}$ hold as equalities. ${ }^{11}$

More interesting are the results regarding the optimal values of $T_{1}$ and $T_{2}$. The impacts on the Lagrangean of a one-period increase in $T_{1}$ or $T_{2}$ are given by (5) and (6) respectively

as:

The condition for $\mathrm{IC}_{1}$ not to bind is that:

$$
\sum_{t=0}^{T_{2}}\left[c\left(q_{2} / N_{1}\right)-c\left(q_{2} / N_{2}\right)\right] \delta^{t}>\sum_{t=0}^{T_{1}}\left[c\left(q_{1} / N_{1}\right)-c\left(q_{1} / N_{2}\right] \delta^{t}\right.
$$

This condition is derived by subtracting the LHS of $\mathrm{IC}_{1}$ from the $\mathrm{RHS}$ of $\mathrm{IC}_{2}$ and vice-versa (recall that $\mathrm{IC}_{2}$ holds as an equality). If $q_{2}>q_{1}$, as will be the case in the optimal contract, then convexity of $C($.$) implies$ that a sufficient condition for the above to be satisfied is that $T_{2} \geq T_{1}$. Clearly, it may also be satified if $T_{2}<T_{1}$.

${ }_{11 \mathrm{Had}} \mathrm{IC}_{1}$ been binding, the only difference in the results would be that $q_{2}$ would be larger than $q_{2}^{*}$. Otherwise, the results would be unaffected. 


$$
\left\{\rho\left(p q_{1}-w_{1}-\pi_{1}+(1-\delta) G\right)-\lambda_{2}\left[w_{1}-c\left(q_{1} / N_{2}\right)-R\right]+\lambda_{1}\left[w_{1}-c\left(q_{1} / N_{1}\right)-R\right]\right\} \delta^{T_{1}+1}
$$

$$
\left\{(1-\rho)\left(p q_{2}-w_{2}-\pi_{2}+(1-\delta) G\right)+\lambda_{2}\left[w_{2}-c\left(q_{2} / N_{2}\right)-R\right]\right\} \delta^{T_{2}+1}
$$

The first thing to note about the above expressions is that their signs are independent of $T_{i}$. This follows from the fact that the values of $q_{1}, q_{2}, \lambda_{1}$ and $\lambda_{2}$ determined in (1)-(4) above are all independent of $T_{i}{ }^{12}$ As a result, the optimal values of $T_{i}$ must be either 0 or $\infty$, with $T_{1}=0$ if the sign of (5) is negative and $T_{1}=\infty$ if (5) is positive. The sign of (6) determines the value of $T_{2}$ in a similar fashion.

Substitution for $\lambda_{1}$ and $\lambda_{2}$ from conditions (2) and (4), allows the bracketed expressions in (5) and (6) to be written as:

$$
\rho\left[\left(p \widehat{q}_{1}-c\left(\widehat{q}_{1} / N_{1}\right)-R\right)-\left(\pi_{1}-(1-\delta) G\right)\right]-(1-\rho)\left[c\left(\widehat{q}_{1} / N_{1}\right)-c\left(\widehat{q}_{1} / N_{2}\right)\right]
$$

and

$$
(1-\rho)\left[\left(p q_{2}^{*}-c\left(q_{2}^{*} / N_{2}\right)-R\right)-\left(\pi_{2}-(1-\delta) G\right)\right]
$$

Inspection of (8) reveals that $T_{2}=0$ if the total one-period returns from utilizing a local agent when $N_{i}=N_{2}$ (the first term in parentheses) are smaller than the one-period returns from the MNE employing its own sales force (the second term). $T_{2}=\infty$ if the opposite is

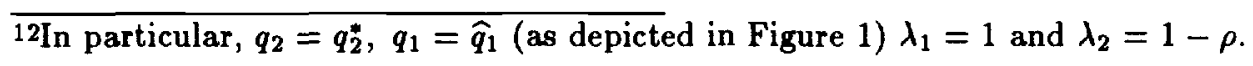




\section{Exploring New Markets: Direct Investment, Contractual Relations and the Multinational Enterprise}

true. The MNE will find an owned sales operation more profitable the smaller are $F$ and $G$ relative to $R$ and the larger is $\alpha$.

As for $T_{1}$, it also is zero if the MNE finds an owned sales operation more profitable when $N_{i}=N_{1}$ than utilizing a local agent (the first bracketed term). However, unlike the situation with $T_{2}$, the opposite ranking of returns does not guarantee that $T_{1}=\infty$. This is because an increase in $T_{1}$ results in an increase in the information rents that must be paid to the agent to induce self selection when $N_{i}=N_{2}$. This increment in expected information rents is given by the second term in (7). Information rents will be small either when $N_{1}$ is close to $N_{2}$ or when $N_{1}$ is very small. ${ }^{13}$ Thus, in addition to having $F$ and $G$ large relative to $R$ and/or $\alpha$ small, $N_{1}$ being either small or close to $N_{2}$ will result in $T_{1}=\infty$. These results are summarized in the proposition below.

Proposition 1: If $F$ and $G$ are small relative to $R$ and $\alpha$ large, then $T_{1}=T_{2}=0$. If $F$ and $G$ are large relative to $R$ and $\alpha$ small and, in addition, either i) $N_{1}$ close to $N_{2}$ or ii) $N_{1}$ small, then $T_{1}=T_{2}=\infty$.

Two other possibilities are: i) $T_{1}=0, T_{2}=\infty$ and ii) $T_{1}=\infty, T_{2}=0$. The former case arises when $F$ and $G$ are sufficiently large relative to $R$ and/or $\alpha$ sufficiently small that the returns from utilizing the local agent are larger than from the MNE employing its own sales force when $N_{i}=N_{2}$. However, when $N_{i}=N_{1}$, information rents are sufficiently large as to $\overline{\text { 13Indeed, } \lim _{N_{1} \rightarrow N_{2}}\left[c\left(\widehat{q}_{1} / N_{1}\right)-c\left(\widehat{q}_{1} / N_{2}\right)\right]}=\lim _{N_{1} \rightarrow 0}\left[c\left(\widehat{q}_{1} / N_{1}\right)-c\left(\widehat{q}_{1} / N_{2}\right)\right]=0$. The reason in the former case is obvious. In the latter case, substitution for $\lambda_{1}$ and $\lambda_{2}$ in (1) reveals that $\widehat{q}_{1}$ must be such that

$$
\rho\left[p-c^{\prime}\left(\widehat{q}_{1} / N_{1}\right) \frac{1}{N_{1}}\right]-(1-\rho)\left[c^{\prime}\left(\widehat{q}_{1} / N_{1}\right) \frac{1}{N_{1}}-c^{\prime}\left(\widehat{q}_{1} / N_{2}\right) \frac{1}{N_{2}}\right]=0
$$

Because $c^{\prime}(0)=0, \widehat{q}_{1}$ is strictly positive for all $N_{1}$ positive and $\widehat{q}_{1} \rightarrow 0$ as $N_{1} \rightarrow 0$. Of course, for this contract to continue to be optimal when $N_{1}$ is small, $R$ must be small also. In particular, if $R$ were zero, this contract would be optimal even as $N_{1}$ approached zero. 


\section{Exploring New Markets: Direct Investment, Contractual Relations and the Multinational Enterprise}

offset any profit advantage the local agent might provide.

The latter case is perhaps the most interesting of the four possibilities and one often found in the data. For this situation to arise, it must be that, when $N_{i}=N_{1}$, the returns from utilizing a local agent are sufficiently large relative to those from an owned sales operation that the differential swamps any costs the MNE expects to incur from paying information rents. At the same time, it must be that, when $N_{i}=N_{2}$, the returns from an owned sales operation are larger than those from utilizing a local agent. The fact that the costs of operating an owned sales operation are lumpy suggests that this outcome is feasible if $N_{2}$ is sufficiently large and $N_{1}$ sufficiently small. The following proposition confirms this intuition by providing conditions on $N_{1}$ and $N_{2}$ sufficient to guarantee that the optimal contract involves the outcome $T_{1}=\infty, T_{2}=0 .{ }^{14}$

Proposition 2: Suppose that i) $R=0$, ii) $\alpha>1$ and iii) $F, G$ such that $0<F+(1-\delta) G<$ $\left\{p q_{2}^{*}(\alpha)-c\left[q_{2}^{*}(\alpha) / \alpha N_{2}\right]\right\}-\left\{p q_{2}^{*}-c\left(q_{2}^{*} / N_{2}\right)\right\}$. Then there exist a value $\underline{N}_{1}>0$ such that, for all $N_{1}<\underline{N}_{1}$, the optimal contract has $T_{1}=\infty, T_{2}=0$.

Proof: Conditions i) and iii) guarantee that (8) is negative and so $T_{2}=0$. Condition ii) guarantees that there are values of $F$ and $G$ such that iii) can be satisfied. Condition i) also guarantees that the program (C2) defines the optimal contract for all values of $N_{1}, N_{2}$. From (1), this program has the feature that $\hat{q}_{1}>0$ for all $N_{1}>0$ and $\widehat{q}_{1} \rightarrow 0$ as $N_{1} \rightarrow 0$. This fact implies that (7) approaches the value $F+(1-\delta) G>0$ as $N_{1} \rightarrow 0$. Thus, for $N_{1}$ sufficiently small, (7) is positive and therefore $T_{1}=\infty$. $\|$

14In the following proposition, the variable $q_{2}^{*}(\alpha)$ refers to the profit maximizing output of the MNE's owned sales operation when $N_{i}=N_{2}$. 


\section{Exploring New Markets: Direct Investment, Contract ual Relations and the Multinational Enterprise}

There are two features of this contract that make it of particular interest. First, the MNE uses a short-term contract to gather information about market size. The contract allows the MNE to convert to an owned sales operation when this sales mode is more profitable and to keep the agency contract when this arrangement is the more profitable one. Second, conversion to FDI occurs when the value of shipments is large while retention of the agency contract occurs when the value of shipments is small. This predicted behavior conforms well to observed outcomes on FDI.

\subsection{The choice between contracting and FDI}

Of course, rather than entering the market initially via a contractual arrangement, the MNE may choose immediate direct investment. Should the MNE's choose this latter option, then we assume as previously that it learns the value of $N_{i}$ in the process of establishing its operations. We also assume that, having established operations, it pays the MNE to operate for at least one-period regardless of the value of $N_{i} \cdot{ }^{15}$ After this one period of operation, the MNE may choose to remain in the foreign country for additional periods or withdraw and sell via a contracted sales agent. In the case of MNE withdrawal from the foreign country, the agency contract will be the full information one since the MNE has learned the value of $N_{i}$.

As for the MNE's choice of initial sales mode, when the optimal contract has either $T_{1}=T_{2}=0$ or $T_{1}=T_{2}=\infty$ (the situations described in proposition 1), the MNE's decision is implied by the values of $T_{i}$. In the former case, the MNE prefers FDI over any contract 15This is an assumption that, by the time the MNE has learned the value of $N_{i}, F$ is sunk for the one-period. 


\section{Exploring New Markets: Direct Investment, Contract ual Relations and the Multinational Enterprise}

with a local sales agent while, in the latter, it prefers a contract involving a permanent arrangement with a local sales agent over FDI. Thus, when the MNE's costs are low relative to the those of the agent and its sales force is more efficient, direct investment will occur initially. If the MNE's costs are high and its sales force less efficient, a permanent agency arrangement will result.

What about the remaining situations; namely, those for which i) $T_{1}=0, T_{2}=\infty$ and ii) $T_{1}=\infty, T_{2}=0$ ? While both types of contracts are legitimate given the MNE's assumed ability to commit, we focus on those situations in which the latter contract is the optimal one. This is done both because we think this case is more relevant empirically and because the former contract suffers from time inconsistency problems that make it unattractive. In particular, this contract has the feature that it would be in both agents' interest to renegotiate the contract to a long-term contract when $N_{i}=N_{1}$. Of course, for those interested in this case, an analysis similar to that below could be carried out for this contract.

Turning to the situation in which the optimal contract is $T_{1}=\infty, T_{2}=0,{ }^{16}$ the MNE's expected profits under this contract are

$$
V^{a}=\rho \frac{p \widehat{q}_{1}-\widehat{w}_{1}}{1-\delta}+(1-\rho)\left[\left(p q_{2}^{*}-\widehat{w}_{2}\right)+\frac{\delta \pi_{2}}{1-\delta}-\delta G\right]
$$

If the MNE chooses FDI initially, then it earns profits of $\pi_{2}$ each period if $N_{i}=N_{2}$. If $N_{i}=N_{1}$, then the MNE earns profits, $\pi_{1}$, in period 1 and profits given by $\max \left[\pi_{1}, p q_{1}^{*}-w_{1}^{*}\right]$ in each subsequent period. This latter expression takes account of the possibility that the 16This is the situation described in proposition 2. 


\section{Exploring New Markets: Direct Investment, Contractual Relations and the Multinational Enterprise}

MNE may find it more profitable to shut-down its operations in the foreign country and sell via a local sales agent. The expression $q_{1}^{*}-w_{1}^{*}$ gives the MNE's per-period profits should it choose this option. ${ }^{17}$ The MNE's expected profits from choosing FDI initially are therefore given by the expression

$$
V^{I}=\rho\left(\pi_{1}+\delta \max \left[\frac{\pi_{1}}{1-\delta}, \frac{p q_{1}^{*}-w_{1}^{*}}{1-\delta}\right]\right)+(1-\rho)\left(\frac{\pi_{2}}{1-\delta}\right)-G
$$

If $V^{I}>V^{a}$, then the MNE chooses FDI initially, while it chooses a contract with the local agent initially if $V^{I}<V^{a}$.

As in the case of the single-period problem, the MNE's decision to contract initially with a local agent or invest in an owned sales operation turns on the balance between the savings associated with the agent arising from lower set-up costs $(G=0)$ and the losses associated with the agent due to lower efficiency at generating customers and agency costs created by the imperfect information. The exact nature of the trade-off between these different elements can be quantified by noting that the difference $V^{I}-V^{a}$ can be expressed as ${ }^{18}$

$$
\begin{gathered}
V^{I}-V^{a}=\left[\rho \pi_{1}+(1-\rho) \pi_{2}\right]-\left[\rho\left(p q_{1}^{*}-w_{1}^{*}\right)+(1-\rho)\left(p q_{2}^{*}-w_{2}^{*}\right)\right]-[G(1-\delta+\rho \delta)] \\
+\frac{\delta \rho}{1-\delta} \max \left[0, \pi_{1}-\left(p q_{1}^{*}-w_{1}^{*}\right)\right]+(1-\rho)\left(\hat{w}_{2}-w_{2}^{*}\right)+\frac{\rho}{1-\delta}\left[\left(p q_{1}^{*}-w_{1}^{*}\right)-\left(p \widehat{q}_{1}-\widehat{w}_{1}\right)\right]
\end{gathered}
$$

The first line of (11) plus the first term in the second line gives the difference between the

MNE's expected profits should it choose FDI and its expected profits were it able to contract

17Recall that the situation under consideration is one in which an owned sales operation is more profitable for the MNE than the agency contract if $N_{i}=N_{2}$, while the opposite is true if $N_{i}=N_{1}$. Because the cost $G$ is sunk once the MNE has invested, however,it may nonetheless find it more profitable to maintain its owned sales operation even if $N_{i}=N_{1}$.

18In calculating the expression below, the value $\frac{\rho}{1-\delta}\left(p q_{1}^{*}-w_{1}^{*}\right)$ has been added and subtracted to the difference $V^{I}-V^{a}$ from (9) and (10). The addition appears in the last term in (11) while the subtraction occurs in the second and fourth terms. The value $(1-\rho) w_{2}^{*}$ has also been added and subtracted. 


\section{Exploring New Markets: Direct Investment, Contractual Relations and the}

Multinational Enterprise

with a local sales agent and implement the full-information outcomes. These terms capture the relevant gains and losses from use of the different selling technologies implied by the local agent as opposed to an owned sales operation. The last two terms in (11) are the agency costs resulting from the fact that the contract with the local agent cannot implement the full-information outcomes. The first of these terms is the information rent that the agent extracts if $N_{i}=N_{2}$ while the second is the profit loss resulting from the fact that $q_{1}$ is distorted away from the full-information level. ${ }^{19}$

If one substitutes out for $w_{1}^{*}, \widehat{w}_{1}, w_{2}^{*}$ and $\widehat{w}_{2}$ using $\mathrm{IR}_{1}, \mathrm{IC}_{2}$ and the $\mathrm{IR}$ constraints for the full-information contracting problem, (11) can be re-written as

$$
\begin{aligned}
V^{I}-V^{a} & =\left[E \pi^{I}-E \pi^{a}\right]-[G(1-\delta+\rho \delta)]+\frac{\delta \rho}{1-\delta} \max \left[0, \pi_{1}-\left[p q_{1}^{*}-c\left(q_{1}^{*} / N_{1}\right)-R\right]\right] \\
& +\frac{1-\rho}{1-\delta}\left[c\left(\hat{q}_{1} / N_{1}\right)-c\left(\hat{q}_{1} / N_{2}\right)\right]+\frac{\rho}{1-\delta}\left(\left[p q_{1}^{*}-c\left(q_{1}^{*} / N_{1}\right)\right]-\left[p \widehat{q}_{1}-c\left(\hat{q}_{1} / N_{1}\right)\right]\right)
\end{aligned}
$$

where the value of $E \pi^{I}$ is given by the expression $E \pi^{I}=\rho \pi_{1}+(1-\rho) \pi_{2}$ and that of $E \pi^{a}$ by $E \pi^{a}=\rho\left[p q_{1}^{*}-c\left(q_{1}^{*} / N_{1}\right)\right]+(1-\rho)\left[p q_{2}^{*}-c\left(q_{2}^{*} / N_{2}\right)\right]-R$. Because (12) contains the maximized value of profits under the two selling modes and also incorporates the relevant constraints from the contracting problem $\left(\mathrm{IC}_{2}\right.$ and $\left.\mathrm{IR}_{1}\right)$, envelope properties can be exploited to determine how the MNE's choice of sales mode is affected by the various parameters of the problem. In particular, any desired comparative statics result can be obtained by simply taking the partial derivative of (12) with respect to the relevant variable. With this fact in hand, we can turn to a consideration of the determinants of the MNE's sales mode choice ${ }^{19}$ Where $\mathrm{IC}_{1}$ binding, there would be an additional agency cost resulting from the fact that $q_{2}$ would be distorted away from $q_{2}^{*}$. In addition, it may be that $T_{2}>0$, implying a further cost under the contract. 


\section{Exploring New Markets: Direct Investment, Contractual Relations and the Multinational Enterprise}

for this case.

Entry via FDI vs. local agent- First, note that both initial entry via FDI and via an agency contract in which $T_{1}=\infty, T_{2}=0$ are possible outcomes. To see this, consider the case in which $R=0, F, G>0, \alpha>1$ and $N_{1}$ small. Recall from proposition 2 that, as $N_{1} \rightarrow 0$, so does $\widehat{q}_{1}$ and $q_{1}^{*}$. As a result, the last two terms in (12) are small when $N_{1}$ is small. In this case, then, the choice between immediate FDI and an agency contract turns essentially on the relative per-period returns of the two modes. That $T_{1}=\infty$ implies that an agency contract yields higher per-period returns when $N_{i}=N_{1}$ while $T_{2}=0$ means that FDI is more profitable when $N_{i}=N_{2}$. Therefore, when the market is likely small ( $\rho$ large) the agency contract will be adopted. In this case, if the market proves small, the agency relationship persists. However, if the market proves large, the agent is replaced by an owned sales operation. If it is likely the market is large ( $\rho$ small), immediate FDI is the preferred mode. In this case, it is possible that the MNE discovers that the market is, in fact, small after entry. If so, the MNE may choose subsequently to exit the market and continue serving it via a local agent. That is, failed FDI may occur.

Market size and the entry decision-Consider the MNE's entry decision in two distinct markets: a large market and a small market. The potential customer pool in the large market is $\beta$-times that in the small market, $\beta>1$ (implying that $N_{1} / N_{2}$ is the same in both markets). How might this difference in market size affect the MNE's mode of entry? To answer this question, note first that, if $\alpha>1$ (as was assumed in proposition 2), $E \pi^{I}-E \pi^{a}>0$ and increasing in both $N_{1}$ and $N_{2}$. The same is true of the third term in 


\section{Exploring New Markets: Direct Investment, Contractual Relations and the \\ Multinational Enterprise}

(12). Large markets allow the MNE to exploit its superior selling ability more than small markets do. This fact makes immediate FDI more likely in the larger market.

What about the effect of market size on agency costs? These costs are given by the last two terms in (12). Differentiation of these terms with respect to $N_{1}$ and $N_{2}$, holding the ratio $N_{1} / N_{2}$ constant, shows that the impact on agency costs of an increase in market size is given by the expression

$$
-\frac{1-\rho}{1-\delta}\left[c^{\prime}\left(\frac{\widehat{q}_{1}}{N_{1}}\right) \frac{\widehat{q}_{1}}{N_{2} N_{1}}-c^{\prime}\left(\frac{\widehat{q}_{1}}{N_{2}}\right) \frac{\widehat{q}_{1}}{N_{2}^{2}}\right]+\frac{\rho}{1-\delta}\left[c^{\prime}\left(\frac{q_{1}^{*}}{N_{1}}\right) \frac{q_{1}^{*}}{N_{1} N_{2}}-c^{\prime}\left(\frac{\widehat{q}_{1}}{N_{1}}\right) \frac{\widehat{q}_{1}}{N_{1} N_{2}}\right]
$$

Adding and subtracting $\rho p \widehat{q}_{1} / N_{2}$ from (13) and noting that $c^{\prime}\left(q_{1}^{*} / N_{1}\right) \frac{1}{N_{1}}=p$, this derivative can be expressed as

$$
\frac{\widehat{q}_{1}}{N_{2}(1-\delta)}\left\{\left[\rho\left(p-c^{\prime}\left(\frac{\hat{q}_{1}}{N_{1}}\right) \frac{1}{N_{1}}\right]-(1-\rho)\left[c^{\prime}\left(\frac{\widehat{q}_{1}}{N_{1}}\right) \frac{1}{N_{1}}-c^{\prime}\left(\frac{\widehat{q}_{1}}{N_{2}}\right) \frac{1}{N_{2}}\right]\right\}+\frac{\rho p}{N_{2}}\left(q_{1}^{*}-\widehat{q}_{1}\right)\right.
$$

From (1) -(4), the first term is zero while the second is positive. Thus, agency costs are also higher in the larger country, again making FDI more attractive. As a result, both because of the greater profitability of FDI in the large country and the greater costs of an agency contract, the MNE is more likely to enter the larger market with FDI and the smaller market with an agency contract.

Profit variability and FDI- In addition to considering how differences in the size of the potential customer pool (average revenues) across markets affects the MNE's entry decision, one might consider how variability in the size of the potential customer pool (variance in 


\section{Exploring New Markets: Direct Investment, Contractual Relations and the Multinational Enterprise}

revenues) within a market affects the MNE's decision. Imagine, for instance, an increase in $N_{2}$ and a corresponding decrease in $N_{1}$ such that $E \pi^{I}$ remains constant. ${ }^{20}$ Such a change leaves expected profits should the MNE choose FDI constant but increases the variance in profits. In general, nothing unambiguous can be said about how such a change affects the MNE's decision. However, if the effort cost function is assumed to be quadratic, then interesting implications can be obtained. The remainder of the sub-section proceeds under this assumption.

Under quadratic costs, the ratio $\frac{q_{1}^{*}(\alpha)}{q_{2}^{*}(\alpha)}=\frac{N_{1}^{2}}{N_{2}^{2}}$ for all $\alpha$. This implies that, if $E \pi^{I}$ remains constant under the proposed changes in $N_{1}$ and $N_{2}$, so does $E \pi^{a}$. Therefore, the first term in (12) remains unchanged while the third term is weakly decreasing. Thus, the increase in profit variability weakly decreases the direct profitability of FDI. How are agency costs affected? The last two terms of (12) capture these costs. Differentiation of these two terms and use of the definitions of $q_{1}^{*}$ and $\hat{q}_{1}$ reveal that the impact on agency costs is given by the sign of the expression $\rho N_{1}^{4}-(1-\rho)\left(N_{2}^{2}-N_{1}^{2}\right)$. If $N_{1}$ is small, as is assumed for the contract $T_{1}=\infty, T_{2}=0$ to be optimal, then increasing profit variability decreases agency costs. The result is that, in markets that are risky in the sense given here, the MNE will choose to enter initially with an agency arrangement. If the market proves profitable, the MNE will convert to an owned sales operation; otherwise, it will keep the agent. In markets that are less risky, 20This change would be given by the expression

$$
\frac{d N_{1}}{d N_{2}}=-\frac{(1-\rho) c^{\prime}\left[q_{2}^{*}(\alpha) / \alpha N_{2}\right] \frac{q_{2}^{*}}{\alpha N_{2}^{2}}}{\rho c^{\prime}\left[q_{1}^{*}(\alpha) / \alpha N_{1}\right] \frac{q_{1}^{*}}{\alpha N_{1}^{2}}}
$$




\section{Exploring New Markets: Direct Investment, Contractual Relations and the Multinational Enterprise}

entry via immediate FDI is the more likely outcome.

Costs and FDI- As $F$ and $G$ increase or $\alpha$ decreases, FDI becomes less profitable relative to an agency arrangement. Indeed, as was seen previously, FDI may be sufficiently costly relative to the agency contract that the MNE simply chooses to enter initially with a contract that is maintained regardless of the size of $N_{i}$.

Contract length and FDI- In what has preceded, it is assumed that the length of time over which profits accrue and the length of time required for the MNE to break the contract and establish its own sales operation are the same. There is no obvious reason that this should be the case (i.e., periods have no natural length). This equivalence can be broken by assuming that profits accrue at $t=1,2, \ldots$ while the contract period is $\Delta t, \Delta \geq 1$. For instance, one might assume that if the MNE wishes to break the contract and establish its own sales operation, it cannot do so before $t=2$. What affect will increasing the length of the initial contract period have? From the previous section, if the MNE cannot convert until $t=2$, then the value to it of the contract is diminished. As a result, $V^{a}$ falls and the value of (12) increases. In essence, increasing the length of the initial contract makes it a less valuable tool for gathering information about the market. As a result, the MNE is less likely to choose the contract over FDI.

\section{Summary and Conclusions}

This paper has considered the decision of a multinational firm either to enter a new market via immediate direct investment or some through contractual arrangement with a local firm. 


\section{Exploring New Markets: Direct Investment, Contractual Relations and the Multinational Enterprise}

If the contractual arrangement is chosen, the contract can be a short-term or long-term one. The gain from contracting with a local agent is that the multinational can avoid possibly costly investment mistakes arising from its unfamiliarity with market characteristics. The cost of contracting is that the firm must transfer some of its rents to the agent due to the superior information the agent possesses (the agency costs of contracting). The multinational may prefer a short-term contract because such a contract allows it to exploit the information it gathers via the agency arrangement. The cost is that the contract results in additional agency costs due to the agents recognition of possible cancellation.

We find that, if the MNE uses a contract initially, it will use a (potentially) shortterm contract when its fixed costs are high relative to the agent's, its sales force more efficient and there is large down-side risk in potential profits. In these circumstances, the contractual arrangement will be maintained if the market proves small (low sales) while it will be cancelled if the market proves large (high sales). As for the MNE's choice of initial entry mode, it is more likely to enter via immediate direct investment (rather than the potentially short-term contract) the larger is the expected market size, the less down-side risk in expected profits and the longer is the time required to convert to owned operations should the market prove large. 


\section{References}

[1] Aghion, P. and P. Bolton (1987), "Contracts as Barriers to Entry", American Economic Review 77, 388-401.

[2] Buckley, Peter J. (editor) (1990), International Investment (Aldershot: Edward Elgar).

[3] Casson, Mark (1987), The Firm and the Market: Studies in Multinational Enterprise and the Scope of the Firm (Oxford: Blackwell and Cambridge: MIT Press).

[4] Casson, Mark (editor) (1990), Multinational Corporations (Aldershot: Edward Elgar).

[5] Caves, Richard E. (1982), Multinational Enterprise and Economic Analysis (Cambridge: Cambridge University Press).

[6] Ethier, Wilfred J. (1986), "The Multinational Firm," Quarterly Journal of Economics, 80, 805-33.

[7] Ethier, Wilfred J. and James R. Markusen (1992), "Multinational Firms, Technology Diffusion and Trade," Working Paper: University of Pennsylvania and NBER.

[8] Horstmann, I. and James Markusen (1987), "Licensing Versus Direct Investment: A Model of Internalization by the Multinational Enterprise," Canadian Journal of Economics 20, 464-481.

[9] ______ (1992), "Exploring New Markets: The Multinational Firm's Choice of Direct Investment Versus Licensing", Institute for Internation Studies: University of Stockholm, Working Paper \#528.

[10] McGahan, A.M., "The Effect of Incomplete Information about Demand on Preemption", International Journal of Indusrial Organization" 11, 327-46.

[11] McIntosh/Baring (1993), The Kangaroo Hops North: An Analysis of Australian Business Opportunities in Asia (Melbourne: McIntosh \& Company).

[12] Myerson, R.B. (1991), Game Theory: Analysis of Conflict. (Cambridge: Harvard University Press).

[13] Nicholas, Stephen (1982), "British Multinational Investment Before 1939", Journal of European Economic History 11, 605-30.

[14] _-___ (1983), "Agency Contracts, Institutional Modes, and the Transition to Foreign Direct Investment by British Manufacturing Multinationals Before 1939," Journal of Economic History 43, 675-686. Reprinted in Mark Casson (editor), Multinational Corporations, Aldershot: Edward Elgar (1990).

[15] Nicholas, S., W. Purcell, D. Merritt and A. Whitwell (1994), "Foreign Direct Investment in Australia in the 1990's", University of Melbourne (unpublished).

[16] Thompson, Allan G. (1994), "Relationship Problems in Australian Business Ventures in Southeast Asia", University of Melbourne Working Paper.

[17] Zeile, William J. (1993), "Merchandise Trade of U.S. Affiliates of Foreign Companies", Survey of Current Business, October, 52- 65. 